\title{
Toxicity on Laboratory Grown Plankton by the Oils Released from the Hebei Spirit Spill with Emphasis on a Dispersant Used in the Aftermath
}

\author{
Keun-Hyung Choi, Sang-Min Lim', Sung-Mi Lee", Gyung-Soo Park ${ }^{1{ }^{1}}$ \\ Korea Institute of Coastal Ecology, Inc., Gyeonggi-do 421-808, Korea

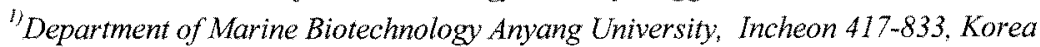 \\ (Manuscript received 31 August, 2009; revised 21 December, 2009; accepted 22 January, 2010)
}

\begin{abstract}
The in vitro toxicities of three crude oils of the Hebei Spirit were examined on laboratory grown plankton, with a focus on the effects of a dispersant. The specific growth rate of phytoplankton and the mortalities of two zooplankton were measured in response to exposure to various concentrations of water accommodated oil, dispersant or both. The effects of the oils varied among the plankton, but were generally low within the range of the oil concentrations used, with little difference in toxicity among the three oils. Such low toxicity appeared to be associated with weathering of the crude oils. Exposure to the dispersant, however, dramatically increased the mortality of zooplankton, with complete inhibition of phytoplankton growth. No synergistic toxic effect was observed with the crude oil and dispersant combination. A better decision making process could be crafted for future application of dispersant in the event of an oil spill in Korean waters to better protect the marine plankton community from the excessive use of dispersant.
\end{abstract}

Key Words : Hebei Spirit, Oil spill, Plankton, Toxicity, Dispersant

\section{Introduction}

A collision between a barge and an oil tanker, the Hebei Spirit, on December 7, 2007, released an estimated 12,000 tons of light crude oil into the waters approximately $10 \mathrm{~km}$ off the Taean Peninsula on the west coast of Korea (Joint UNEP/OCHA Environment Unit, 2008). The spill was recorded as the most disastrous in Korean waters with respect to the volume of crude oil discharged, at more than twice that in the Sea Prince spill in 1995, South Korea's previous worst spill, which leaked over 5,000 tons of crude oil into the southern sea of Korea and destroyed over 3,000 ha of marine aquaculture area,

\footnotetext{
"Corresponding author : Gyung-Soo Park, Department of Marine Biotechnology Anyang University, Incheon 417-833, Korea Phone: $+82-32-930-6032$

E-mail: gspark@anyang.ac.kr
}

with significant reduction in the number of benthic species (MOERI, 2002).

Three different medium grade crude oils (specific gravity of 0.85), UAE Upper Zakum, Kuwait Export and Iranian Heavy, were reported to be released from the Hebei Spirit, with nearly $261 \mathrm{~m}^{3}$ of dispersant (Type 1) being sprayed overnight over the spill area to disperse the oil from the surface (Joint UNEP/ OCHA Environment Unit, 2008). The initial efforts; however, failed to contain the spill, partly due to the bad weather conditions in the winter. The emulsified oil and tar balls spread further south over the following weeks, reaching as far as Jeju Island (approximately $375 \mathrm{~km}$ south of the spill site) by early January 2008 (Kannan, 2009).

One of the areas most affected by the oil spill was Taean National Marine Park, immediately adjacent to 
the east of the spill location, which is significant for fishing, aquaculture and tourism, with more than 21 million people per year, as well as the inhabiting endangered wild populations (e.g., Neophocaena phocaenoides, finless porpoise) in and around the habitats (Shin et al., 2009). A macrofauna survey conducted in December 2007 and January 2008 in the subtidal sediments of the Taean area showed a drastic decrease of $40 \%$ in the numbers of species recorded, $63 \%$ in density and $77 \%$ in biomass compared to the levels for the same period of 2006, with the greatest decline observed in Mollusks (Shin et al., 2009). An initial assessment using laboratory toxicity tests was also conducted during January and February, 2008, which showed that the benthic amphipod, Monocorophium sp., exposed to the oil-contaminated sediment resulted in 90-100\% mortality within 10 days of exposure (Shin et al., 2009). Fertilized fish eggs exposed to the oil contaminated sediment pore-water showed variable mortality in the affected regions, ranging from no impact to $90 \%$ mortality (Shin et al., 2009).

Although the affected marine community on the shore is often the most visible, the planktonic community is also a major group affected by an oil spill from the onset. The coastal area around Taean is a highly productive ecosystem, with a high density of zooplankton, larvae of crabs and other benthic organisms (Shin et al., 2009). The impact of the water accommodated oil fraction on marine plankton is highly variable, depending on the type of oil, the species and life stage being studied ( Al-Yamani et al., 1998; Cowles and Remillard, 1983; O'Brien, 1989; Seikai and Nakamuro, 2002). The concentrations of the crude and refined oils tested suppressed photosynthesis to varying degrees (Anderson et al., 1974; Gordon and Prouse, 1973) found that the water soluble fraction of two different crude oils were toxic to crustacean and fish species at concentrations ranging from 10 to 19 ppm (Anderson et al., 1974). A reduction in the brood size of the harpacticoid copepod, Nitocra affinis, was observed in the water-soluble fraction of crude oil at a concentration of $200 \mathrm{ppb}$ and found total mortality of a harpacticoid copepod within three days with 1 ppm of diesel oil (Barnett and Kontogiannis, 1975; Ustach, 1979). Berdugo et al (1977) observed considerable zooplankton mortality in three days, even with a lower concentration of water-soluble fraction of crude oil $(<1$ ppm). Centropages hamatus, a calanoid copepod, showed a marked decline in ingestion rate and egg hatching success in response to exposure to crude oil (Cowles and Remillard, 1983).

Meanwhile, there have been reports of no effects on plankton due to oil ( Joint UNEP/OCHA Environment Unit, 2008; McGinnis, 1971; Oguri and Kanter, 1971). Studies following the Santa Barbara blowout at an offshore drilling rig in 1969 detected no harmful effects on phytoplankton productivity (Oguri and Kanter, 1971) or zooplankton populations from the spill (McGinnis, 1971), although it would be difficult to discern effects in the field, especially in open waters. Boesch et al. (1974) and Varela et al. (2006) reported no detectable effects on phytoplankton in the spring following the Prestige spill accident that the changes in chlorophyll varied within the range of previous years. The lack of impact was attributed to the low solubility and concentration of aromatic hydrocarbons in the oil (Varela et al., 2006). An oil spill can even stimulate growth of plankton (Fleeger and Chandler, 1983; Naidu et al., 1978). Copepod density was higher in experimentally oiled sites in an Alaskan mudflat than at control sites (Naidu et al., 1978). At a very low oil concentration, the growth of phytoplankton was stimulated, although it was repressed at higher concentrations (Gordon and Prouse, 1973).

These variable results suggest the necessity to test the ecological impact in each oil spill event and of the dispersant used. Investigation of the post-spill effects on the marine community is underway, which 
should reveal the full scale of the impact on marine ecosystems. In the interim, the in vitro the acute effects of the seawater accommodated oil were examined, with specific focus on the dispersant used, on commonly found coastal phytoplankton and zooplankton. We did not measure the hydrocarbon concentration in the oil-water mixture. Rather this study was aimed at the relative effect of dispersant compared with oil. This study may provide an insight to the ecological impact in open waters that may have occurred in the aftermath of the spill.

\section{Materials and Methods}

\subsection{Culturing test organisms}

One phytoplankton and two zooplankton were used in this experiment testing oil toxicity. Isochrysis galbana, a phytoplankton, was obtained from Korea Microalgae Culture Center (KMCC), and has been maintained in $\mathrm{f} / 2$ media at $23-24^{\circ} \mathrm{C}$ under continuous illumination (3,000-4,000 Lux) in the laboratory for over 1 year. Cysts of Brachionus plicatilis, a rotifer, were hatched in the laboratory at $25^{\circ} \mathrm{C}$, a salinity of 10-15 and 500-2,000 Lux, and then were maintained on Chlorella vulgaris as food. Both male and female Tigriopus japonicus, a harpacticoid zooplankton (commonly known as tide pool copepod), were placed together in containers, and fed twice daily a mixture (2:1) of two phytoplankton, Tetraselmis suecica and Isochrysis galbana. Mating produced nauplii of Tigriopus japonicus, which also remained in the same container as the adults.

\subsection{Preparation of water accommodated oil}

Three different oils, Upper Zakum, Kuwait Export and Iranian Heavy, were collected from oil tanks of the Hebei Spirit on December 24, 2007, about two weeks after the spill occurred. The oil samples and dispersant used in the spill area were sent to our laboratory on January 272008 . The water- accommodated fraction of crude oil (WAF) was prepared within a day of arrival of the samples. One part $(30 \mathrm{ml})$ of each of the three oils was placed over 9 parts $(670$ $\mathrm{ml}$ ) of filter-sterilized seawater in a 11 bottle, which was then shaken vigorously on a shaker for $8 \mathrm{hr}$. The water accommodated dispersant-oil fraction (WADF) was prepared by mixing $24 \mathrm{ml}$ of Upper Zakum crude oil with $6 \mathrm{ml}$ of dispersant and $670 \mathrm{ml}$ of seawater, which was treated in the same way as the WAF. The mixture was allowed to stand for six hours for separation of the oil from seawater; the separated aqueous phase was drained into a second container and used as a stock solution for the toxicity tests. These stock solutions of WAF or WADF were then serially and geometrically diluted with filtered seawater, ranging from no dilution to the lowest concentration of $0.78 \%$ of WAF or WADF.

\subsection{Dilution series exposures}

The toxicity test of the plankton was conducted on Jan. 29, 2008. WAF, WADF or dispersant was serially diluted with autoclaved seawater (salinity of $30.5 \%$ ), with autoclaved seawater serving as the negative control. Isochrysis galbana was inoculated into $30 \mathrm{ml}$ of the treated seawater for $72 \mathrm{hr}$ under the same conditions used for culturing the phytoplankton, with three replicates conducted for each treatment. The specific growth rate of the phytoplankton was computed from the net change in the cell concentration between the beginning and the end of the incubation (Lee et al., 2008).

Ten rotifers were placed in each well of 6 well plates, with three replicates conducted for each treatment concentration, with $5 \mathrm{ml}$ of treated seawater in each well. Only those that hatched within $2 \mathrm{hr}$ from the cysts $(83 \mathrm{\mu m}$ in length) were used in the experiment. The rotifers in the well plates were incubated, without food, for $24 \mathrm{hr}$ at $25{ }^{\circ} \mathrm{C}$ in the dark. The number of dead animals was enumerated at the end of the experiment using microscopy (Park et al., 2008). 
Nauplii of Tigriopus japonicus, produced by mating of adult males and females in the culture bath, were screened to obtain only those in the range $100-200 \mu \mathrm{m}$. Twenty were added to each of twelve 6-well plate vessels, with three replicate vessels for each oil treatment, plus three control vessels receiving uncontaminated autoclaved seawater. The nauplii were incubated for $48 \mathrm{hr}$ at $25^{\circ} \mathrm{C}$, without food, under a $16 \mathrm{hr}$-light and $8 \mathrm{hr}$-dark illumination cycle.

\subsection{Statistical analyses}

A Dunnet's test was performed to estimate the no observed effect concentration (NOEC) and lowest observed-effect concentration (LOEC). A generalized linear model was used to calculate the half maximal effective concentration $\left(\mathrm{EC}_{50}\right)$ for phytoplankton growth or the lethal concentration of toxicant at which half the test organisms died $\left(\mathrm{LC}_{50}\right)$ for the two zooplankton and their $95 \%$ confidence limits ( $R$ Development Core Team, 2006).

\subsection{Quality control of the tests}

Care was taken to ensure the measurements in the controls met the required conditions, that being a phytoplankton growth rate in the controls exceeded $0.04 \mathrm{~h}^{-1}$ (Lee et al., 2008), with mortality of zooplankton in the controls did not exceed $10 \%$ by the last day of the experiment (Park et al., 2008). Survival rate of the zooplankton in the controls was good, with only one animal lost out of 10 individuals in each batch by the last day of the experiment for the two zooplankton.

\section{Results}

The results of the in vitro bioassays of the oil and dispersant toxicities on plankton were rather complex. The specific growth rate of $I$. galbana was negatively affected only at WAF concentrations of $50 \%$ (equivalent to $21 \%$ of WAF) or higher (Fig. 1 and Table 1). Kuwait Export crude oil was apparently less deleterious to phytoplankton growth than the Upper Zakum and Iranian Heavy. Exposure of the phytoplankton

Table 1. No observed effect concentration (NOEC) and lowest observed-effect concentration (LOEC) for the test plankton, with the half maximal effective concentration $\left(\mathrm{EC}_{50}\right)$ and lethal concentration of toxicant at which half the test organisms died $\left(\mathrm{LC}_{50}\right)$ and the $95 \%$ binomial confidence limit (CL)

\begin{tabular}{|c|c|c|c|c|}
\hline $\begin{array}{l}\text { Test organism } \\
\text { and treatment }\end{array}$ & NOEC (\%) & LOEC (\%) & $\begin{array}{l}\mathrm{EC}_{50}(\%) / \\
\mathrm{LC}_{50}(\%)\end{array}$ & $95 \% \mathrm{CL}$ \\
\hline \multicolumn{5}{|l|}{ Isochrysis galbana } \\
\hline Upper Zakum & 25 & 50 & & \\
\hline Kuwait Export & 50 & 100 & & \\
\hline Iranian Heavy & 25 & 50 & & \\
\hline dispersant & 0 & $<0.78$ & & \\
\hline Upper Zakum + dispersant & 0 & $<0.78$ & & \\
\hline \multicolumn{5}{|l|}{ Brachionus plicatilis } \\
\hline Upper Zakum & 100 & $>100$ & & \\
\hline Kuwait Export & 100 & $>100$ & & \\
\hline Iranian Heavy & 12.5 & 25.0 & & \\
\hline dispersant & $<1.56$ & 1.56 & 1.4 & $0.9-2.2$ \\
\hline Upper Zakum + dispersant & 0.78 & 0.78 & 2.4 & $2.0-3.0$ \\
\hline \multicolumn{5}{|l|}{ Tigriopus japonicus } \\
\hline Upper Zakum & 25.0 & 50.0 & & \\
\hline Kuwait Export & $<6.25$ & 6.25 & & \\
\hline Iranian Heavy & 6.25 & 12.5 & & \\
\hline dispersant & $<1.56$ & 1.56 & 1.9 & $1.3-2.8$ \\
\hline Upper Zakum + dispersant & $<0.78$ & 1.56 & 3.1 & $2.4-4.0$ \\
\hline
\end{tabular}




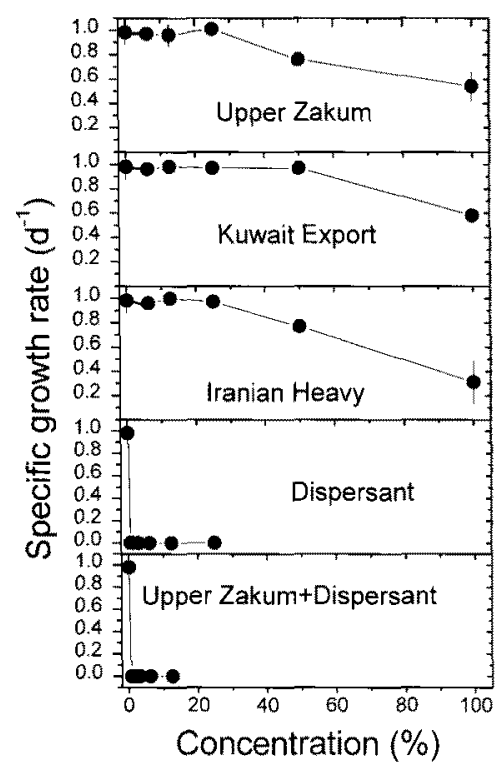

Fig. 1. Specific growth rate $\left(\mathrm{D}^{-1}\right)$ of Isochrysis galbana exposed for $72 \mathrm{hrs}$ to various concentrations of the three different water-accommodated fraction of crude oil (WAF) or water accommodated dispersantoil fraction (WADF).

to the dispersant was striking, completely inhibiting the growth of the phytoplankton at the lowest concentration used $(<1 \%$, equivalent to $130 \mathrm{ppm}$ of WAF), with no difference shown in the toxicity from the phytoplankton batch cultures exposed to WADF.

The mortality of the rotifer, Brachionus plicatilis, at all WAF concentrations tested for the Upper Zakum aforKuwait $\mathrm{m}$ afrt oils showed no difference from those of the controls (i.e, those exposed to sr water onls), but the the Upper Za oil showed greater mortality, with UppLOmC at 25r (Fig. 2, Taby, 1). The nauplii of Tigriopus japonicus weKuwsusceptiby, to all three oils, but affected most by Iranian Heavy oil, followed by Kuwait Export and then Upper Zakum.

Consistent with the response of the phytoplankton, the addition of dispersant to the culture drastically increased the mortalities of the two zooplankton, with little difference in toxicity from the batches exposed to WADF (Fig. 2 and 3). The mean $\mathrm{LC}_{50}$ was

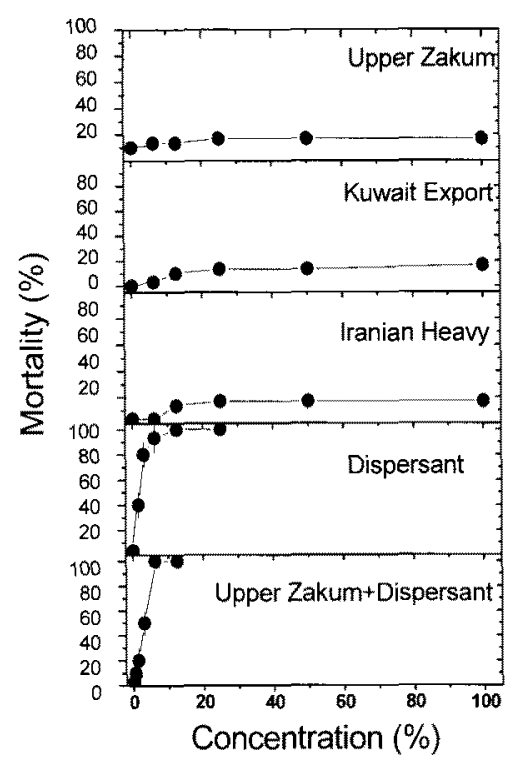

Fig. 2. Mortality (\%) of Brachionus plicatilis exposed for 24 hrs to various concentrations of the three different water-accommodated fraction of crude oil (WAF) or water accommodated dispersant-oil fraction (WADF).

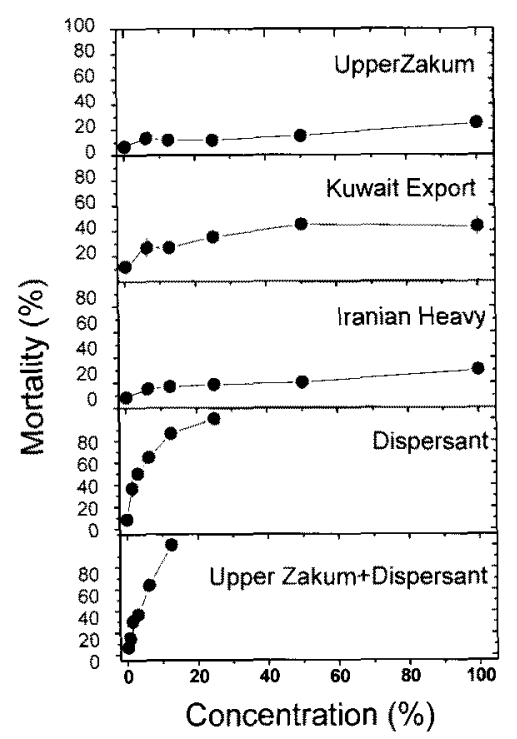

Fig. 3. Mortality (\%) of Tigriopus japonicus nauplii exposed for $48 \mathrm{hrs}$ to various concentrations of the three different water-accommodated fraction of crude oil (WAF) or water accommodated dispersantoil fraction (WADF). 
generally higher for the batches exposed to dispersant than the zooplankton treated with WADF, with the $95 \%$ confidence limit for $\mathrm{LC}_{50}$ overlapping between the two treatments, suggesting there was no synergistic toxicity effect toward both zooplankton by the crude oil and dispersant combined.

\section{Discussion}

The toxicity of the oil was positively correlated with the concentration of low-molecular weight hydrocarbons rather than the total hydrocarbon concentration (Di Toro et al., 2007). Immediately after a spill, the lightest fractions and the most toxic components of oil, composed of polycyclic aromatic hydrocarbons (PAHs), generally evaporate less than a day after a spill (Walker et al., 2001), with possibly low ecological impact due to their limited time to mix with seawater. The total hydrocarbon concentration in seawater rapidly decreases, by more than $50 \%$ in the first few days (Dalla Venezia and Fossato, 1977). Intermediate molecular weight aromatics (three to four rings PAHs), the next most toxic components, are more persistent, with their solubility in water being high enough to cause toxicity to pelagic organisms (Bellas and Thor, 2007). High molecular weight PAHs generally pose no short-term risk to pelagic organisms due to their extremely low solubility in water (Albers, 1995). The replacement of more with less toxically potent compounds lowers the toxicity (Di Toro et al., 2007).

The physical effect of the dispersants in emulsifying oil often results in increased toxicity. Many studies have found that the PAH (with benzen rings of 3-4) concentration is much higher in chemically-dispersed oil than that for physicallydispersed oil (Fingas, 2008), with higher toxicity (Fingas, 2008; Michel et al., 2005) and faster bioaccumulation of PAH (Wolfe et al., 1998). Combining oil with dispersants has been found to increase the toxicity of the oil to a crab species by a factor of 16 (Ahsanullah et al., 1982). A dispersant without oil showed low toxicity, but become more toxic in the presence oil, in that nearly $100 \%$ of larvae were deformed after hatching when exposed to a combination of $50 \mathrm{ppb}$ of dispersant and $200 \mathrm{ppb}$ of heavy C-oil (Seikai and Nakamuro, 2002).

In the present study, the toxicity of the three different oils was limited, and did not exceed $25 \%$ of the mortality of the highest concentration used (approximately 40 parts per thousands), even for the nauplii of $T$. japonicus (Fig. 2 and Table 1), the life stage considered most susceptible to toxicants. Furthermore, there appeared to be no synergistic toxicity effect from the combination of dispersant and oil. Instead, much of the toxicity came from the dispersant, which may, in part, have resulted from the high concentration of dispersant used (130 ppm for the lowest concentration used) in this study. However, some dispersants resulted in lower toxicity, even at higher concentrations than that used in this study (Wilson, 1977). Most dispersants available in Korea consist of surfactants $(30 \%)$ and hydrocarbon solvents (70\%) (Shin, 2008), implying potentially high toxicity, although formulae with less toxicity are also available. The low impact of the crude oil on the plankton observed in this study and the lack of a synergistic effect of the combination may be associated with the weathering of the crude oils (Bobra et al., 1983; Di Toro et al., 2007) during the month since the sampling of the oils on board the Hebei Spirit, given that the initial toxicity assessments on other organisms was high by the same spilled crude oils from the Hebei Spirit (Shin et al., 2009).

Their toxic effects aside, the efficacy of dispersant on spills is controversial (Fingas, 2008), varying with environmental factors, such as water temperature and viscosity. The viscosity of oil increases rapidly with weathering (Committee, 2005), with the oil becoming 
more difficult to disperse. It is important, therefore, to add dispersant within a few hours to obtain maximum efficiency (Duke and Petrazzuolo, 1989). The oil dispersion efficacy becomes reduced at low temperatures (e.g., in winter; the season time of this spill event) (Duke and Petrazzuolo, 1989). From a reviewing over 430 papers on oil spill dispersant, published between 1997 and 2008, it was concluded that dispersants somewhat inhibit oil biodegradation or have no effect on biodegradation, with no evidence of enhanced biodegradation as a result of dispersant use (Fingas, 2008). Taken together, these observations indicate potentially limited efficacy of the dispersant applied during the aftermath of the oil spill from the Hebei Spirit.

The post-spill impact of the water extract of crude oil on the plankton community is difficult to be estimated. However, a couple of field observations support the adverse effects on zooplankton community. Cho et al. (2008) surveyed the zooplankton community in January 2008, about the time our laboratory tests were performed. Their results showed a lower zooplankton abundance in the vicinity of the spill area than in the southern waters further from the spill center. In addition, a post-spill zooplankton survey off the Taean Peninsula, conducted in December 2007 and the following January, also showed that the total zooplankton abundance had decreased compared to the level during the same sampling period in 2006 (Shin et al., 2009). It is not clear if in 200n impact on the zooplankton community could be attributed to crude oil, or more to the dispersants applied on the sea-surface, having a much higher toxicity impact than that manifested by the dispersants in the laboratory study (Fig. 2 and 3). Dispersants are likely to be toxic to marine organisms, given their chemical composition, with serious consequences to some marine organisms, as demonstrated in this in vitro toxicity study. Better decision making processes could be crafted for future applications of dispersants, with particular reference to their toxicity and efficacy, in the event of an oil spill in Korean waters to better protect the marine life from excessive dispersant use.

\section{References}

Ahsanullah, M., Edwards, R. R. C., Kay, D. G., Negilski, D. S., 1982, Acute toxicity to the crab Paragrapsus quadridentatus (H. Milne Edwards), of Kuwait light crude oil, BP/AB dispersant, and an oil-dispersant mixture, Aust. J. Mar. Freshwat. Res., 33, 459-464.

Albers, P. H., 1995, Petroleum and individual polycyclic aromatic hydrocarbons. in: Hoffman D. J., Rattner, B. A., Burton, C. A., Cairns, J. Jr. (eds.), Handbook of Ecotoxicology, Lewis Publishers, Boca Raton, 330-355.

Al-Yamani, F., Al-Rifaie, K., Al-Mutairi, H., Ismail, W., 1998, Post-spill spatial distribution of zooplankton in the ROPME Sea Area, in: Otsuki A., Abdulraheem, M. Y., Reynolds, R. M. (eds.), Offshore Environment of the ROPME Sea Area after the War-Related Oil Spill, Terra Scientific Publishing Company (TERRAPUB), 193-202.

Anderson, J. W., Neff, J. M., Cox, B. A., Tatem, H. E., Hightower, G. M., 1974, Characteristics of dispersions and water-soluble extracts of crude and refined oils and their toxicity to estuarine crustaceans and fish, Mar. Biol., 27, 75-88.

Barnett, C. J., Kontogiannis, J. E., 1975, The effect of crude oil fractions on the survival of a tidepool copepod, Tigriopus califonicus, Environ. Pollut., 8, 45-54.

Bellas, J., Thor, P., 2007, Effects of selected PAHs on reproduction and survival of the calanoid copepod Acartia tonsa, Ecotoxicology, 16, 465-474.

Berdugo, V., Harris, R. P., O'Hara, S. C., 1977, The effect of petroleum hydrocarbons on reproduction of an estuarine planktonic copepod in laboratory cultures, Mar. Pollut. Bull., 8, 138-43.

Bobra, A. M., Shiu, W. U., Mackay, D., 1983, Acute toxicity of fresh and weathered crude oils to Daphnia magna. Chemosphere, 12, 1137-1149.

Boesch, D. F., Hershner, C. H., Milgram, J. H., 1974, Oil spill and marine environment, Ballinger Publishing Company, 124. 
Cho, S. G., Kim, B. H., Bak, D. S., 2008, Winter zooplankton community structure in the oil spill area of Taean Marine National Park, 2008 Conference of Korean Society of Marine Environmental Engineering, 142.

Committee, 2005, Oil Spill Dispersant: Efficacy and Effects. National Research Council, 400, http://ww w. nap.edu/catalog/11283.html.

Cowles, T. J., Remillard, J. F., 1983, Effects of exposure to sublethal concentrations of crude oil on the copepod Centropages hamatus, Mar. Biol., 78, 45-51.

Dalla Venezia, L., Fossato, V. U., 1977, Characteristics of suspensions of Kuwait oil and Corexit 7664 and their short and long-term effects on Tisbe bulblsetosa (Copepoda: Harpacticoida), Mar. Biol., 42, 233-237.

Di Toro, D. M., McGrath, J. A., Stubblefield, W. A., 2007, Predicting the toxicity of neat and weathered crude oil: toxic potential and the toxicity of saturated mixtures, Environ. Toxicol. Chem., 26, 24-36.

Duke, T. W., Petrazzuolo, G., 1989, Oil and dispersant toxicity testing. Proceedings of a Workshop on Technical Specifications Held in New Orleans, 139.

Fingas, M., 2008, A review of literature related to oil spill dispersant especially relevant to Alaska, http://www.pwsrcac.org/docs/d0052000.pdf.

Fleeger, J. W., Chandler, G. T., 1983, Meiofauna responses to an experimental oil spill in a Louisiana salt marsh, Mar. Ecol. Prog. Ser., 11, 257-264.

Gordon, D. C., Prouse, N. J., 1973, The effects of three oils on marine phytoplankton photosynthesis, Mar. Biol., 22, 329-333.

Joint UNEP/OCHA Environment Unit, 2008, Rapid Environmental Assessment Hebei Spirit Oil Spill. Republic of Korea, December 2007, 38.

Kannan, N., 2009, Hebei Spirit oil spill in Korea, http://www.scitopics.com/Habei_Spirit_Oil_Spill.

Lee, S. M., Park, G. S., An, K. H., Park, Y. S., Lee, S. H., 2008, Application of the ecotoxicological standard method using population growth inhibition of marine phytoplankton, J. Korean Soc. Ocean., 13, 112-120.

McGinnis, D. R., 1971, Observations on the zooplankton of the eastern Santa Barbara Channel from May, 1969, to March, 1970, in: Straughan, D. (ed.), Biological and Oceanographical Survey of the Santa Barbara Channel Oil Spill 1969 - 1970, Alan
Hancock Foundation, University of Southern California, Los Angeles, 49-53.

Michel, J., Shigenaka, G., Hoff, R., 2005, Oil spill response and cleanup techniques, http://response. restoration.noaa.gov/book_shelf/681_Chapter5.pdf.

MOERI, 2002, Post-accident management of oil pollution of the Sea Prince, Korea Ministry of Land, Transportation, and Maritime Affairs, 296.

Naidu, A. A., Feder, H. M., Norrell,S. A., 1978, The effect of Prudhoe Bay crude oil on a tidal-flat ecosystem in Port Valdez, Alaska. Tenth Offshore Technology Conference, Houston, Texas, 97-104.

O'Brien, W. J., 1989, Toxicity of Prudhoe Bay crude oil to Alaskan Arctic zooplankton, Arctic, 31, 214-228.

Oguri, M., Kanter, R., 1971, Primary productivity in the Santa Barbara Channel, in: Straughan, D. (ed.), Biological and Oceanographical Survey of the Santa Barbara Channel Oil Spill 1969 - 1970, Alan Hancock Foundation, University of Southern California, Los Angeles, 17-48.

Park, G. S., Lee, S. M., Han, T. J., Lee, J. S., 2008, Establishment of standard methods for marine ecotoxicological test, J. Korean Soc. Ocean., 13, 106-111.

R Development Core Team, 2006, R: a language and environment for statistical computing. $R$ Foundation for statistical computing, Vienna, Austria, http://www. r-project.org/.

Seikai, T., Nakamuro, K., 2002, Effects of spilled oil from tanker, Nakhodka, and dispersant on the embryonic stage of marine fish and zooplankton, in: Tasaki, K, (ed.) Towards Eco-responsibility, Earth Sense, Kanazawa University, 105-122.

Shin, C. H., Chang, J. I., Choi, J. Y., 2009, Estimate of the Environmental Damage of Oil Pollution Accident by the Hebei Spirit. Korea Maritime Institute, 24.

Shin, Y. S., 2008, Taean oil leakage accidents and future challenges; Taean oil leak and restore the environmental effects of the accident, Monthly Land, 325, 15-24.

Ustach, J. F., 1979, Effects of sublethal oil concentrations on the copepod, Nitocra affinis, Estuaries, 2, 273-276.

Varela, M., Bode, A., Lorenzo, J., Alvarez- Ossorio, M. T., Miranda, A., Patrocinio, T., Anadón, R., Viesca, L., Rodríguez, N., Valdés, L., Cabal, J., Urrutia, Á., Garcia-Soto, C., Rodríguez, M., Álvarez-Salgado, 
X.A., Groom, S., 2006, The effect of the "Prestige" oil spill on the plankton of the N-NW Spanish coast, Mar. Pollut. Bull., 53, 272-286.

Walker, C. H., Hopkin, S. P., Sibly, R. M., Peakall, D. B., 2001, Principles of Ecotoxicology; 2nd ed., Taylor and Francis, 309.

Wilson, K. W., 1977, Acute toxicity of oil dispersants to marine fish larvae, Mar. Biol., 40, 65-74.

Wolfe, M. F., Schlosser, J. A., Schwartz, G. J. B., Singaram, S., Mielbrecht, E. E., Tjeerdema, R. S., Sowby, M. L., 1998, Influence of dispersants on the bioavailability and trophic transfer of petroleum hydrocarbons to primary levels of a marine food chain, Aquatic Toxicol., 42, 211-227. 